\title{
Mobile internet and technology for optical teaching reform in higher education
}

\section{Muchun Zhou, Qi Zhao, Yanru Chen}

Muchun Zhou, Qi Zhao, Yanru Chen, "Mobile internet and technology for optical teaching reform in higher education," Proc. SPIE 10452, 14th Conference on Education and Training in Optics and Photonics: ETOP 2017, 104525K (16 August 2017); doi: 10.1117/12.2269762

SPIE Event: 14th Conference on Education and Training in Optics and Photonics, ETOP 2017, 2017, Hangzhou, China 


\title{
Mobile Internet and Technology for Optical Teaching Reform in Higher Education
}

\author{
Muchun Zhou*, Qi Zhao, Yanru Chen \\ School of Electronic and Optical Engineering, Nanjing University of Science and Technology, \\ NO. 200, Xiaoling Wei Street, Nanjing, China, 210094
}

\begin{abstract}
There are some problems in optical education such as insufficient flexibility, individuality and adaptability to students who need information and education at present. The development of mobile internet and technology provides support to solve these problems. Basic characteristics, advantages and developments of these techniques used in education are presented in this paper. Mobile internet is introduced to reform the classroom teaching of optical courses. Mobile network tool selection, teaching resources construction and reform in teaching methods are discussed. Academic record and sampling surveys are used to assess intention to adopt mobile internet and learning effect of academic major of students, the results show that high quality optical education can be offered by adopting mobile internet and technologies in traditional instruction.
\end{abstract}

Keywords: mobile learning, optical education, effectiveness, university students

\section{INTRODUCTION}

Over the past few decades, the number of mobile users in the world has increased significantly. In fact, according to the last report of International Telecommunications Unit (ITU, 2016) there were seven billion people (95\% of the global population) live in an area that is covered by a mobile-cellular network. The 39th "China Internet Development Statistics Report" shows that as of December 2016, the number of Chinese mobile phone users reached 695 million. The use of mobile devices such as cell phones and PADs has grown to such an extent in recent years that they are beyond the proliferation of personal computers in modern professional and social environments ${ }^{1}$. The ready availability and uptake of these devices has permeated the means of human communication, socializing and entertainment ${ }^{2}$. Step by step, people have got used to these devices, which have provided new ways of communication, interacting each other, getting information or even learning ${ }^{3}$.In fact, one of the rising trends of the past few years is the use of new technologies within the scope of education, especially the use of mobile devices and their education, which is called mobile learning (mlearning) ${ }^{4}$. There are different ways of defining mobile learning, a widely accepted and common used definition of mobile learning proposed by Alexander, is learning that is wireless and ubiquitous so the idea of wearable computing is very well applied to m-learning 5 .

There are many reports related with the use of mobile learning. Najmul Hasan presented an idea about mobile internet based education all over the globe and its applicability in Bangladesh along with investigating the developing progress of ICT in educational institutions and educational organization related activities ${ }^{6}$.Joanne Gikas explored teaching and learning when mobile computing devices were implemented in higher education, found that mobile computing devices and the use of social media created opportunities for interaction, provided opportunities for collaboration ${ }^{7}$. Zahra Taleba studied the students' viewpoints about the educational use of mobile technology to support their learning process, among 2140 students of psychology and educational science ${ }^{8}$. Jongpil Cheon investigated mobile learning readiness in higher education based on the theory of planned behavior ${ }^{3}$. Defining, discussing, and evaluating mobile learning were articulated in ref [9]. Strategic solutions for learning types development and integration of advanced technologies in different forms of education are presented in ref [10]. Laura Briz-Ponce tried to research about the different factors and drivers that could influence students' behavior into the usage of mobile technologies for learning, and described the main characteristics and the use of mobile technologies in education ${ }^{1,11}$.

On the other hand, optics has important applications in research and engineering, optical education has become the focus

*mczhou@sohu.com;

14th Conference on Education and Training in Optics and Photonics: ETOP 2017, edited by Xu Liu,

Xi-Cheng Zhang, Proc. of SPIE Vol. 10452, 104525K · @ 2017 ICO, IEEE, OSA, SPIE

CCC code: $0277-786 X / 17 / \$ 18 \cdot$ doi: $10.1117 / 12.2269762$

Proc. of SPIE Vol. 10452 104525K-1 
of attention ${ }^{12,13,14}$. Optical courses are usually difficult for students for there are too many complicate models and formulas which are abstract. Online courses can not provide interactive communication with the teachers, problems arising from the student's learning process can not be solved in time. Due to the lack of traditional instruction, students are easily disoriented. Basic problems of traditional optical education are insufficient flexibility, individuality and adaptability to learners needs of education whenever and wherever it is necessary ${ }^{6}$.Mobile education can make up for these shortcomings because it has the advantages of (a) accessing information quickly, (b) supporting a variety of learning styles, (c) communication and content collaboration ${ }^{1}$.The purpose of this paper is to explore new methods of integrating mobile internet technology into traditional optical instruction, which can give full play to the leading role of teachers and the main role of students, and make teaching more attractive to students. Teaching reform of "engineering optics" course of optics education is discussed in this paper.

\section{MOBILE TECHNOLOGIES INTEGRATION IN TRADITIONAL CLASSROOM INSTRUCTION}

\subsection{Establish mobile network teaching platform}

The use of mobile networks and technologies can extend optical classroom instruction beyond the classroom. Compared with the traditional classroom teaching model, mobile learning is an extension of traditional classroom teaching in time and space. Therefore, it is necessary to establish a virtual optical classroom, that is, the internet platform of learning optics resources. The platform is a learning carrier with interactive features such as information release, topic discussion exchange, resource sharing, learning experience sharing, and troubleshooting, etc. Resources such as e-books, periodicals and other resources from the library can be integrated into the platform, and the latest information collected by teachers, research experience, students' learning experience and other information can also be put into the platform. When students need access to course information, search for the platform to get results quickly. Interactive accessing to mobile resource platform is shown in Figure 1.

Interaction is the key to effective learning and information exchange. Mobile interaction does not subject to time and space constraints in mobile internet situation, teaching and learning interaction can be done anytime, anywhere, and the interactive process is more vivid than the traditional way and can arouse students' interest. This process requires networking tools to quickly access the platform and communicate. Social networking sites and tools such as blog, microblogg, QQ and WeChat are the latest examples of communications technologies that have been widely-adopted by students and, consequently, have the potential to become a valuable resource to support their educational communications and collaborations with faculty in China. Instant messaging tools and self-media are suitable for introducing as a means of communication. SMS mode, is to send information to each other's mobile phone, by the text content limit, the form is not rich enough and without group interaction, so being rarely used. Blog is an open platform, most of the information and discussion are open, the user does not even have to register the account can also browse the blog information. Blog content can be targeted, according to the different learning projects and topics to publish different content, making learning more intuitive and effective. Compared to the blog, micro-blog released a short message content, is more convenient to use on the phone, and has better interactivity.

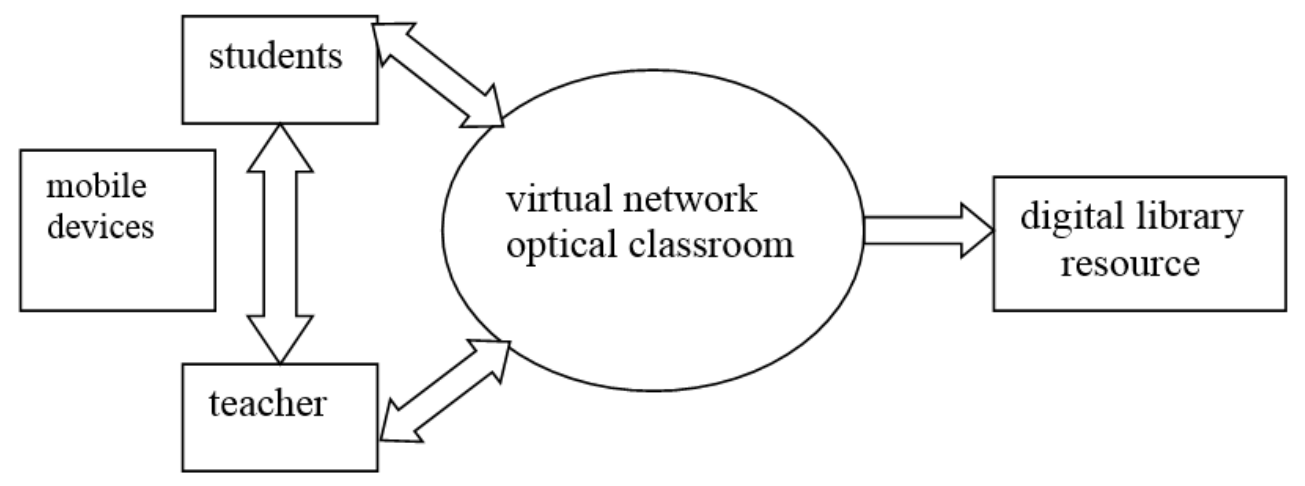

Figure 1. Interactive accessing to mobile resource platform

QQ and WeChat are the most frequently used instant messaging tools in China, text or voice communication function can be used for learning and counseling. The use of QQ group and discussion group function allows us to facilitate team 
discussions and resource sharing, and the use of group bulletin can publish important notice and information. QQ also has a group video function, allows us to easily achieve remote video teaching between teachers and students and among students. Unlike QQ, WeChat is a communication tool for mobile phone users. Another type of communication tools is APP that are specifically developed for mobile learning. In general, mobile learning APPs can provide learning functions such as course creation, graphic publishing, video on demand service, practice examination service, performance analysis, learning analysis, etc.

\subsection{Adjust course content and knowledge structure}

Mobile learning and traditional classroom learning can support and complement each other. According to their own characteristics, the content should be reasonably set up, and the primary and secondary levels should be clear, so as to meet the needs of most students. The class hours in the university classroom are relatively limited, so some content can be placed on the mobile platform for students to choose the right time to learn outside the classroom.

In addition there are individual differences between students, reflected in the way of learning styles, learning interest, the degree of understanding and acceptance of learning content. Some of the content in the classroom may not be fully accepted by students who are slow to respond, can be supplemented in more detail on the mobile platform. For the smarter classmates, content in classroom cannot meet their learning needs, some novel or difficult content can be published on the mobile platform for them.

The optical professional courses, involving more professional knowledge which is area of students' difficulty, include a large number of formulas and computational deduction and other more in-depth content knowledge. These contents are not suitable for mobile platform to learn and master quickly. Mobile learning is learning with non-fixed state, highly decentralized, fragmented, and accessing anytime, anywhere so the content of curriculum for mobile learning should be loose, distributed, and be accessible in the most appropriate form when and where it is necessary.

In view of this situation, it is necessary to classify the optical course content, and there is a distinction between classroom learning and mobile learning. The key principles and methods such as different models in optics are taught in the classroom, and other fragmentary knowledge, as a supplement to the classroom content, can be published on the mobile resource platform. The knowledge unit on the mobile platform should be short and concise, so as to facilitate the learners to complete a learning unit in a short time. The knowledge unit should present a loose knowledge relationship, but the loose content should be able to reflect a certain knowledge association, and gradually form a coherent conceptual framework in the process of continuous learning.

\subsection{Resources construction}

In order to be combined with classroom teaching, mobile network teaching platform should provide learners with a wealth of online teaching resources. According to the characteristics of the specific optical courses and the focus of each chapter, combined with the characteristics of mobile learning, we set up a number of learning resources. Resource types include PPT corresponding to the curriculum content, the extension and expansion of curriculum content, test exercises related to curriculum content, the latest research results of optical literature, news links to important optical events, common optical phenomena etc. Optics is closely related to life, such as the natural and astronomical phenomena, which can be related to the optical principles behind them. These optical phenomena in life can be designed as knowledge points such as a test question, a small game, etc. In this way, a learning theme is created, learners can complete a learning point in an independent time, and students' learning interest can be stimulated in the same time. Resources can be text, pictures, video, network links, flash or other forms of display, the degree of difficulty is different, which can reflect the individual and adaptability, interactivity of learning.

Teachers should not only consider the traditional teaching mode, but also take into account the characteristics of mobile internet applications when making courseware ppt. Compared with the traditional PC, mobile internet terminal network has the characteristics of slow connection, operation ability is relatively limited, small screen, battery life is weak, but has the advantage of small, portable, easy to use and accurate positioning and intelligent perception etc. These features determine the teacher's courseware to be short and exquisite, could be displayed in user-friendly manner on mobile devices displays.

\subsection{Improving teaching methods}

As an extension of classroom learning, mobile learning can expand the study to the outside of classroom learning. Based on the virtual curriculum platform, students preview and master the basic knowledge in accordance with the syllabus and 
requirements of the teachers before each course. Classroom teaching can be used as a way of thinking and exploring. In the classroom, the mobile platform can also be introduced to enrich the classroom teaching methods. Some discussion cases, design cases, test exercises are designed to build basic skills and basic conceptual knowledge, and placed on the mobile platform, as a supplement to classroom knowledge in classroom teaching. We often take typical optical phenomena such as interference and diffraction as example to explain the wave model, and optical instruments such as telescopes and microscopes to imaging characteristics.

After the course, courseware and quiz consistent with classroom content are designed for students to review, so that students know their mastery of the course. According to the statistical results of the mobile platform background, teachers know accurately the problems in students' learning, so as to send specialized counseling resources to help them consolidate learning content. The whole process is shown in Figure 2.

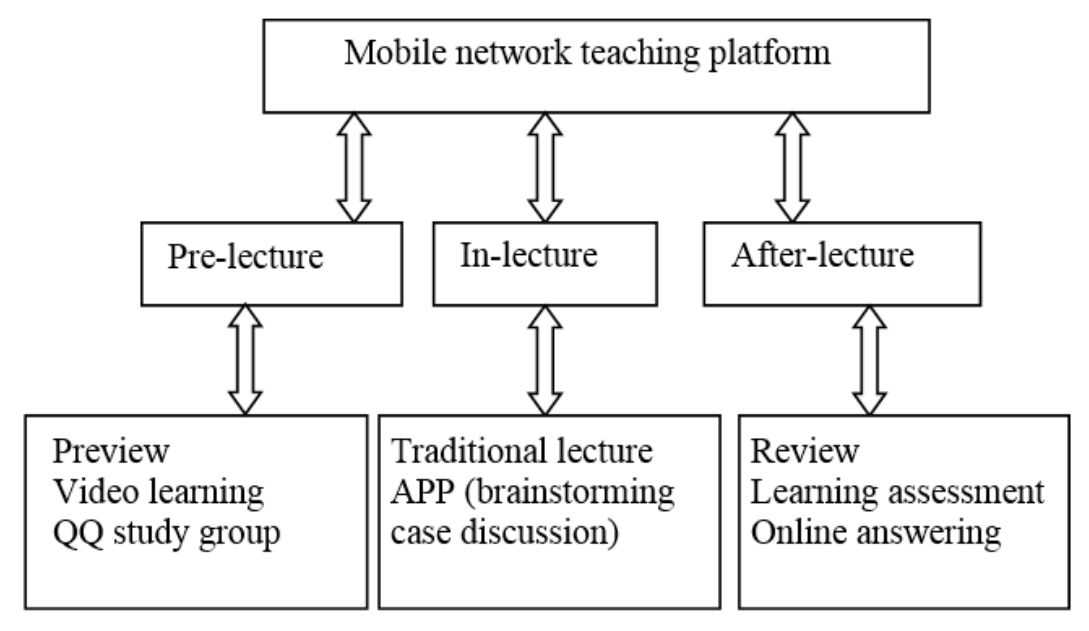

Figure 2. Integration of classroom and network instruction

With the development of mobile technology and the popularity of mobile terminals, many new ideas are provided for the development of teaching and learning. We tried several new ways in the teaching of optics.

As a new teaching mode, the flipped classroom changes the teaching method of teaching and listening. It makes students have sufficient time for thinking, and they can get teachers help in time when they have difficulties. The content of classroom teaching is not teaching knowledge, but students' self-learning. The development of information and technology has brought the education revolution, which provides us the opportunity of realizing the flipped classroom model.

Encourage students to express and share their views, learning is a process of acceptance, understanding to re-creation, expressing their understanding is an in-depth study. We provide functions on mobile teaching platform to students for the free exchange of ideas in problem solving.

Only when learning occurs in the interaction between the individual and the situation, students have deep understanding of relationships and differences among concepts. We often contact with a variety of optical phenomena in life and different optical instruments in optical laboratory, so the optics education is very suitable for situation learning, mobile technology provides a good support for learning scenarios. Lack of connections among concepts, formal representations, and the real world in traditional instruction can be made up by mobile virtual classroom.

\section{EVALUATION OF TEACHING METHODS}

In addition to the traditional classroom teaching, we also utilized the QQ group and mobile teaching APP for the extracurricular teaching of optical courses, and set up a mobile teaching resources platform which has the functions of resource sharing, group discussion, brainstorming, practice test, attendance signature and so on. The network platform is easy to access from the mobile devices. 
In different classes and different courses, we tried new teaching method based on mobile network. The effect of the new teaching method was verified by two method:(1) observation and practice of teachers to students and (2) academic record and sampling surveys which include the students' willingness to use the mobile platform, the tendency of mobile tools and the support of the new teaching methods before course and after course respectively. The results show that students' willingness to learn has been improved, and the scores are improved. Teaching methods can stimulate the students ' learning interests and thirst for knowledge, arouse the study zeal.

\section{CONCLUSION}

By taking the advantages of mobile network and mobile technologies, we built a virtual optics classroom which contains a variety of multimedia information such as text, picture, audio, video, these contents are the supplement of classroom, and are more attractive to students. The virtual optics classroom is open for students to access information and knowledge anywhere, anytime. Based on the virtual classroom, we have created a teaching resource library, adjusted the teaching content, and adopted new teaching methods. With the rapid development of mobile internet and mobile technology, Combination the mobile network with the traditional education breaks the limits of time and space, can realize the interaction between teachers and students, enhance the timeliness and influence of optical teaching, and satisfy the mobility and individuality of optical teaching.

The application of new teaching methods still have some challenges, such as how to stimulate and maintain learners' motivation and interest of participating in mobile learning, teachers need to pay more time and effort, difficulties in the use of software by teachers or students, how to avoid excessive dependence on mobile devices and game addiction, and stable mobile network.

\section{ACKNOWLEDGEMENTS}

This research has been funded by the teaching reform project and network course construction project of Nanjing University of Science and Technology.

\section{REFERENCES}

[1] Briz-Ponce, Laura, Pereira Anabela et al, "Learning with mobile technologies-Students' behavior," Computers in Human Behavior, 1-9 (2016).

[2] Herrington, Jan, et al, "Using mobile technologies to develop new ways of teaching and learning," University of Wollongong, 1-14 (2009).

[3] Cheon, J., Lee, S., Crooks, S. M., \& Song, J., "An investigation of mobile learning readiness in higher education based on the theory of planned behavior," Computers \& Education 59(3), 1054-1064 (2012).

[4] Briz-Ponce, L., Juanes-Méndez, J. A., \& García-Peñalvo, F. J., "Analysis of mobile devices as a support tool for professional medical education in the university school," Proceedings of EDULEARN, 4653-4658 (2014).

[5] Br. Alexander., Going Nomadic. , "Mobile Learning in Higher Education," EDUCAUSE Review, 39(5), 28-35 (2004).

[6] Hasan, N., Ashraf, M. M., Abdullah, A. B. M., \& Murad, M. W. ,"Introducing mobile internet as a learning assistant for secondary and higher secondary students," The Journal of Developing Areas, 50(5), 41-55 (2016).

[7] Gikas, Joanne, and Michael M. Grant., "Mobile computing devices in higher education: Student perspectives on learning with cellphones, smartphones \& social media," The Internet and Higher Education 19, 18-26 (2013).

[8] Taleb, Zahra, and Amir Sohrabi., "Learning on the move: the use of mobile technology to support learning for university students," Procedia-Social and Behavioral Sciences 69, 1102-1109 (2012).

[9] Traxler, John, "Defining, Discussing and Evaluating Mobile Learning: The moving finger writes and having writ....," The International Review of Research in Open and Distributed Learning 8(2), 1-12 (2007).

[10] Yordanova, Korneliya, "Mobile learning and integration of advanced technologies in education," Proceedings of the 2007 international conference on Computer systems and technologies. ACM, (2007).

[11] Briz-Ponce, Laura, and Juan Antonio Juanes-Méndez., "Mobile devices and apps, characteristics and current potential on learning," Journal of Information Technology Research (JITR) 8(4), 26-37 (2015). 
[12] Colin, P., and L. Viennot., "Using two models in optics: Students' difficulties and suggestions for teaching," American Journal of Physics 69(S1) S36-S44 (2001).

[13] Şengören, S. K. ,"How do Turkish high school graduates use the wave theory of light to explain optics phenomena?," Physics Education 45(3), 253-263 (2010).

[14] Galili, Igal, and Amnon Hazan., "The effect of a history-based course in optics on students' views about science," Science \& Education 10(1), 7-32 (2001). 